\title{
Stabilization of Real Inverted Pendulum Using Pole Separation Factor
}

\author{
Amr A. Roshdy* \\ College of Mechanical and Electric Engineering \\ Changchun University of Science and Technology \\ Changchun, China \\ amr.roshdy35@yahoo.com
}

\section{Hany F. Mokbel}

College of Mechanical and Electric Engineering Changchun University of Science and Technology

Changchun, China

\author{
Yu zheng Lin \\ College of Mechanical and Electric Engineering \\ Changchun University of Science and Technology \\ Changchun, China \\ Tongyu Wang \\ College of Mechanical and Electric Engineering \\ Changchun University of Science and Technology \\ Changchun, China
}

\begin{abstract}
Based on the pole placement design technique, a full state feed back controller using separation factor is proposed to stabilize a real single inverted pendulum. The strategy is to start with selection two dominant poles that achieve a certain desired performance, using a separation factor between the selected dominant poles and the other poles to eliminate their effect on the system performance, and finally Ackermann's formula can be used to calculate the feed back gain matrix to place the system poles at the desired locations. Simulation and experimental results demonstrate the effectiveness of the proposed controller, which offers an excellent stabilizing and also ability to overcome the external resistance acting on the pendulum system.
\end{abstract}

Key words-Inverted pendulum, separation factor, state feedback controller

\section{INTODUCTION}

The single inverted pendulum is a classical problem in the field of non-linear control theory; it also offers a good example for control engineers to verify a modern control theory. The inverted pendulum is a highly nonlinear and open-loop unstable system. The characteristics of the inverted pendulum make identification and control more challenging. Inverted pendulum can be considered as a popular system that is used to approximate highly complex models such as rockets during liftoff, bipedal walking, cranes, robots, and etc.

Several control strategies based on the conventional control theory, modern control theory, and intelligent control have been used to control the inverted pendulum, such as PID controller [1, 2], linear quadratic regulator (LQR) [3-5], fuzzy logic controller (FLC) [6-8]. In [9] JiaJan Wang introduced a simple scheme to design a conventional PID controller to stabilize and track three types of inverted pendulum. Although PID controller is a good controller for controlling the single-input-single-output
(SISO) systems, only one PID controller can not be able to control both the cart position and the pendulum angle.

On the other side, modern control theory is based on the description of system equations in terms of $\mathrm{n}$ first-order differential equations, and the system can be described by state space equation form. This means that only one controller can successfully stabilize the inverted pendulum system. The main design approach for systems described in state-space form is the use of state feedback, or pole placement. The first step in the pole placement design approach is to choose the locations of the desired closed loop poles. The most frequently used approach is to choose such poles based on experience in the root locus design, placing a dominant pair of closed poles and choosing other poles so that they are far to the left of the dominant closed loop poles. Another approach is based on the quadratic optimal control approach. This approach will determine the desired closed-loop poles such that it balances between the acceptable response and the amount of control energy required.

In [10] Yan Lan presented a controller design based on state space pole placement method for a non-linear dynamic system described by an inverted pendulum. In [11], Huan made a comparison between several types of controller such as PID, FLC, and state feedback. In [12] Prasad used the inverted pendulum as a benchmark for implementing the control methods. PID controller and two types of fuzzy inference systems are implemented to justify the comparative advantages of fuzzy control methods.

In this paper, the design of the state feed back controller based on pole placement approach using separation factor is given in details. This scheme makes the inverted pendulum control design very easy based on pole placement approach. The real single inverted pendulum experiment is used to verify the effectiveness and the robustness of the proposed control method. 
The remaining part of this paper is organized in the following manner. In section II, the mathematical modeling of the real inverted pendulum is introduced. The design steps of the proposed controller are presented in section III. Simulations and experimental results are presented in section $\mathrm{V}$ and section IV respectively. Finally the conclusions are presented in section VI.

\section{MATHEMATICAL MODELING}

After ignoring the air resistance and a variety of friction, the linear inverted pendulum can be abstracted into a cart and a homogeneous rod, shown in Figure 1.

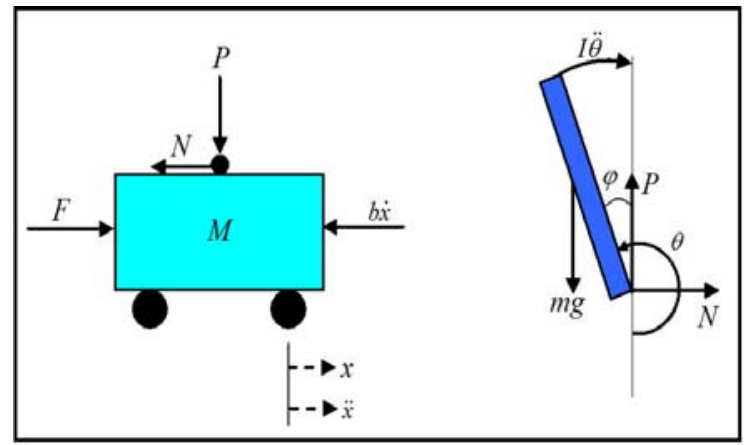

Figure 1 Pendulum system force analysis.

From the sum of force in both horizontal and vertical directions and the sum of moments around the centroid of the pendulum, the system can be described by the following two nonlinear differential equations [13]:

$$
\begin{aligned}
& (\mathrm{M}+\mathrm{m}) \ddot{\mathrm{x}}+\mathrm{b} \dot{\mathrm{x}}-\mathrm{ml} \ddot{\phi}=\mathrm{u} \\
& \left(\mathrm{I}+\mathrm{ml}^{2}\right) \ddot{\phi}-\mathrm{mgl} \phi=\mathrm{ml} \ddot{\mathrm{x}}
\end{aligned}
$$

Where:

\section{Cart mass.}

m Rod mass.

b Friction coefficient of the cart.

1 Distance from the rod axis rotation center to the rod mass center.

I Rod inertia.

F Force acting on the cart.

$\mathrm{x} \quad$ Cart position.

$\Phi \quad$ The angle of the pendulum with the vertical upward direction.

$\theta$ The angle of the pendulum and the vertical downward direction (taking into account the initial position of the pendulum for vertical down).

A set of state variables sufficient to describe this system are chosen as the position and velocity of the cart, the angular position and change of angular position of the pendulum. Therefore, the equations that describe the behavior of the inverted pendulum are as the following:

$$
\begin{aligned}
& \dot{\mathrm{x}}=\dot{\mathrm{x}} \\
& \ddot{\mathrm{x}}=\frac{-\left(\mathrm{I}+\mathrm{ml}^{2}\right) \mathrm{b}}{\mathrm{I}(\mathrm{M}+\mathrm{m})+\mathrm{Mml} \mathrm{f}^{2}} \dot{\mathrm{x}}+\frac{\mathrm{m}^{2} \mathrm{gl}^{2}}{\mathrm{I}(\mathrm{M}+\mathrm{m})+\mathrm{Mml}^{2}} \phi+\frac{\left(\mathrm{I}+\mathrm{ml}^{2}\right)}{\mathrm{I}(\mathrm{M}+\mathrm{m})+\mathrm{Mml}^{2}} \mathrm{u} \\
& \dot{\phi}=\dot{\phi} \\
& \ddot{\phi}=\frac{-\mathrm{mlb}}{\mathrm{I}(\mathrm{M}+\mathrm{m})+M \mathrm{ml}^{2}} \dot{\mathrm{x}}+\frac{\mathrm{mg}(\mathrm{M}+\mathrm{m})}{\mathrm{I}(\mathrm{M}+\mathrm{m})+\mathrm{Mml}^{2}} \phi+\frac{\mathrm{ml}}{\mathrm{I}(\mathrm{M}+\mathrm{m})+\mathrm{Mml}^{2}} \mathrm{u}
\end{aligned}
$$

The system state-space equation can be written as follow:

$$
\begin{aligned}
& \dot{\mathrm{x}}=\mathrm{Ax}+\mathrm{Bu} \\
& \mathrm{y}=\mathrm{Cx}+\mathrm{Du} \\
& {\left[\begin{array}{c}
\dot{\mathrm{x}} \\
\ddot{\mathrm{x}} \\
\dot{\phi} \\
\ddot{\phi}
\end{array}\right]=\left[\begin{array}{cccc}
0 & 1 & 0 & 0 \\
0 & \frac{-\left(\mathrm{I}+\mathrm{ml}^{2}\right) \mathrm{b}}{\mathrm{I}(\mathrm{M}+\mathrm{m})+\mathrm{Mml}^{2}} & \frac{\mathrm{m}^{2} \mathrm{gl}^{2}}{\mathrm{I}(\mathrm{M}+\mathrm{m})+\mathrm{Mml}^{2}} & 0 \\
0 & 0 & 0 & 1 \\
0 & \frac{-\mathrm{mlb}}{\mathrm{I}(\mathrm{M}+\mathrm{m})+\mathrm{Mml}^{2}} & \frac{\mathrm{mgl}(\mathrm{M}+\mathrm{m})}{\mathrm{I}(\mathrm{M}+\mathrm{m})+\mathrm{Mml}^{2}} & 0
\end{array}\right]\left[\begin{array}{c}
\mathrm{x} \\
\dot{\mathrm{x}} \\
\phi \\
\dot{\phi}
\end{array}\right]} \\
& +\left[\begin{array}{c}
0 \\
\frac{\mathrm{I}+\mathrm{ml}^{2}}{\mathrm{I}(\mathrm{M}+\mathrm{m})+\mathrm{Mml}^{2}} \\
0 \\
\frac{\mathrm{ml}}{\mathrm{I}(\mathrm{M}+\mathrm{m})+\mathrm{Mml}^{2}}
\end{array}\right] \mathrm{u} \\
& \mathrm{y}=\left[\begin{array}{l}
\mathrm{x} \\
\phi
\end{array}\right]=\left[\begin{array}{llll}
1 & 0 & 0 & 0 \\
0 & 0 & 1 & 0
\end{array}\right]\left[\begin{array}{c}
\mathrm{x} \\
\dot{\mathrm{x}} \\
\phi \\
\dot{\phi}
\end{array}\right]+\left[\begin{array}{l}
0 \\
0
\end{array}\right] \mathrm{u}
\end{aligned}
$$

For uniform mass distribution of the pendulum:

$$
\mathrm{I}=\frac{1}{3} \mathrm{ml}^{2}
$$

Equation (2) can be written as:

$$
\left(\frac{1}{3} \mathrm{ml}^{2}+\mathrm{ml}^{2}\right) \ddot{\phi}-\mathrm{mgl} \phi=\mathrm{ml} \ddot{\mathrm{x}}
$$

By simplification of (8), we can get:

$$
\ddot{\phi}=\frac{3 \mathrm{~g}}{41} \phi+\frac{3}{41} \ddot{\mathrm{x}}
$$

Finally, the system state-space equation can be written as follow:

$$
\left[\begin{array}{c}
\dot{\mathrm{x}} \\
\ddot{\mathrm{x}} \\
\dot{\phi} \\
\ddot{\phi}
\end{array}\right]=\left[\begin{array}{cccc}
0 & 1 & 0 & 0 \\
0 & 0 & 0 & 0 \\
0 & 0 & 0 & 1 \\
0 & 0 & \frac{3 \mathrm{~g}}{41} & 0
\end{array}\right]\left[\begin{array}{c}
\mathrm{x} \\
\dot{\mathrm{x}} \\
\phi \\
\dot{\phi}
\end{array}\right]+\left[\begin{array}{c}
0 \\
1 \\
0 \\
\frac{3}{41}
\end{array}\right] \mathrm{u}
$$




$$
\mathrm{y}=\left[\begin{array}{l}
\mathrm{x} \\
\phi
\end{array}\right]=\left[\begin{array}{llll}
1 & 0 & 0 & 0 \\
0 & 0 & 1 & 0
\end{array}\right]\left[\begin{array}{l}
\mathrm{x} \\
\dot{\mathrm{x}} \\
\phi \\
\dot{\phi}
\end{array}\right]+\left[\begin{array}{l}
0 \\
0
\end{array}\right] \mathrm{u}
$$

\section{Controller design}

The pendulum system can be controlled using full state feedback. Figure 2 shows the schematic diagram of this type of control system with reference input $r$.

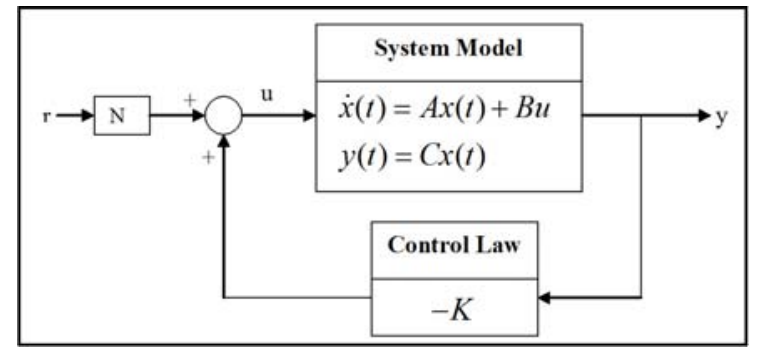

Figure 2 Schematic diagram for one stage inverted pendulum in state space form.

The first step in designing this type of controller is to determine the open loop poles of the system as shown in figure.1. It can be seen that the system is unstable.

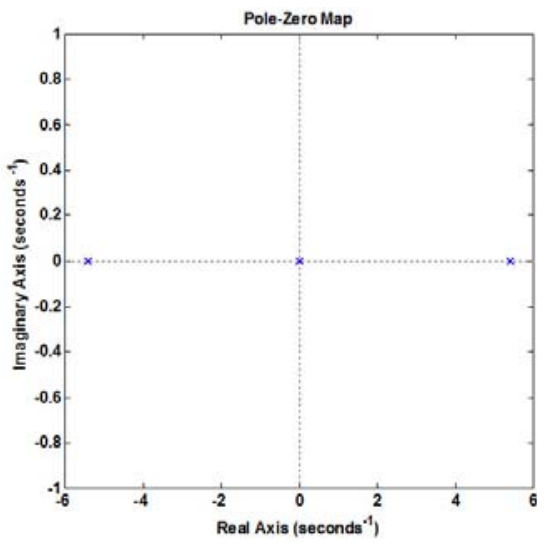

Figure 3 Open loop system pole maps.

The second step in the design process is to assume that the system have full state feedback. The feedback control law is determined by finding the feed back gain vector $\mathrm{K}$ according to the desired closed loop poles location.

For the desired closed loop system characteristics equation given by:

$$
\mathrm{q}(\lambda)=\left(\mathrm{s}^{2}+2 \zeta \omega_{\mathrm{n}} \mathrm{s}+\omega_{\mathrm{n}}^{2}\right)\left(\mathrm{s}^{2}+\mathrm{as}+\mathrm{b}\right)
$$

The pair $\left(\zeta, \omega_{\mathrm{n}}\right)$ are chosen so that the two poles are the dominant poles according to the required performance, and the pair $(a, b)$ are chosen farther in the left half plane using separation factor so as not to be dominant the response.

$$
(\mathrm{a}, \mathrm{b})=\left(\mathrm{s} \zeta,\left(\mathrm{s} \omega_{\mathrm{n}}\right)^{2}\right)
$$

Where, $\mathrm{s}$ is the separation factor between dominant poles and other poles. The separation factor between the dominant poles and the other poles is a parameter that can vary as part of the design process.

Using Ackermann's formula, the vector K can be calculated as:

Where

$$
\mathrm{K}=\left[\begin{array}{llll}
0 & 0 & \ldots 0 & 1
\end{array}\right] \mathrm{P}_{\mathrm{c}}^{-1} \mathrm{q}(\mathrm{A})
$$

$$
\mathrm{q}(\lambda)=\lambda^{\mathrm{n}}+\alpha_{\mathrm{n}-1} \lambda^{\mathrm{n}-1}+\cdots \alpha_{1} \lambda+\alpha_{0} \mathrm{I}
$$

And $\mathrm{P}_{\mathrm{c}}$ is the controllability matrix.

\section{SIMULITION RESULTS}

Simulation study is carried out based on the system model depicted in section II. The system parameters values are listed in table 1.

\section{TABLE I. LIST OF SYSTEM PARAMETERS.}

\begin{tabular}{|c|c|}
\hline System Parameters & Values \\
\hline $\mathrm{M}(\mathrm{kg})$ & 1.096 \\
\hline $\mathrm{m}(\mathrm{kg})$ & 0.109 \\
\hline $\mathrm{b}(\mathrm{Nm} / \mathrm{s})$ & 0.1 \\
\hline $\mathrm{l}(\mathrm{m})$ & 0.25 \\
\hline $\mathrm{I}(\mathrm{kg} . \mathrm{m} . \mathrm{m})$ & 0.0034 \\
\hline
\end{tabular}

In order to obtain a small settling time and low overshoot, $\left(\zeta, \omega_{n}\right)$ are chosen as $(0.858,4.66)$. The separation factor of 2 between the dominant poles and the remaining poles is chosen by simulation which follows that $(a, b)=(1.716,86.8624)$. The desired roots are then specified to be:

$\operatorname{det}(\lambda \mathrm{I}-(\mathrm{A}-\mathrm{BK}))=(\lambda+8 \pm 4.7893 \mathrm{j})(\lambda+4 \pm 2.3946 \mathrm{j})(16)$

The dominant poles are at $\lambda=-4 \pm 2.3946 \mathrm{j}$. Figure 4 shows the closed loop system poles

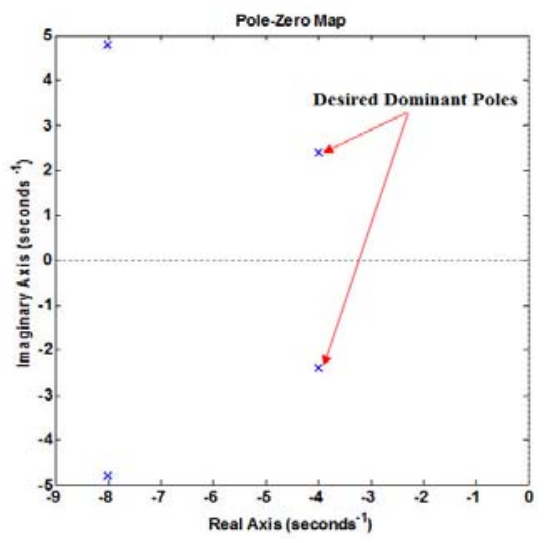

Figure 4 Closed loop system pole map.

The feed back gain matrix $\mathrm{K}$ is calculated as:

$$
\mathrm{K}=\left[\begin{array}{llll}
-64.2693 & -35.4846 & 110.1136 & 19.8282
\end{array}\right]
$$

The step response of the controlled system is shown in figure 5 .it can be seen that both the pendulum angle and cart position satisfy the design requirement. The values of the overshoot, settling time, and the steady state error are 
presented in table 2 for cart position and pendulum angle responses.

TBLE II. RESPONSE MEASURE FOR CART POSITION AND PENDULUM ANGLE

\begin{tabular}{|l|c|c|c|}
\hline & $\begin{array}{c}\text { Percent of } \\
\text { overshoot }\end{array}$ & Setting time & $\begin{array}{c}\text { Steady- } \\
\text { state error }\end{array}$ \\
\hline Cart Position & $1.71 \%$ & $0.897 \mathrm{~s}$ & 0 \\
\hline Pendulum angle & - & $1.5 \mathrm{~s}$ & 0 \\
\hline
\end{tabular}

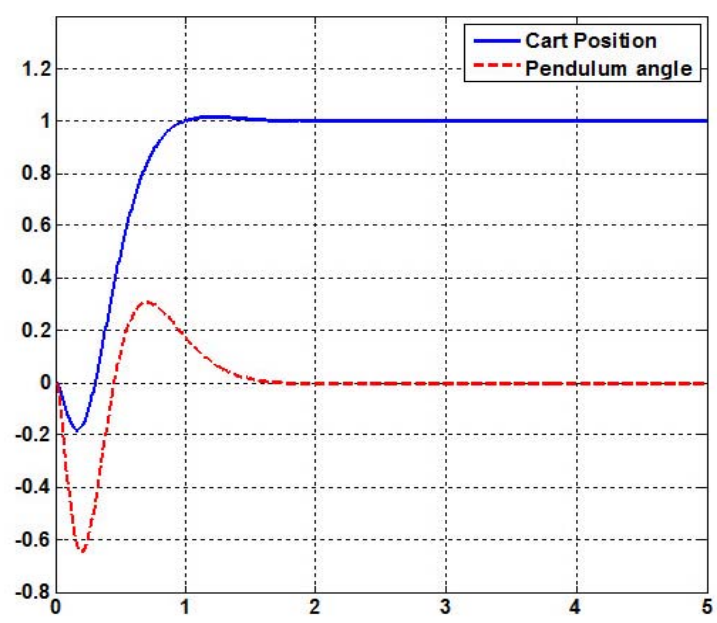

Figure 5 Step response of the pendulum system.

\section{SYSTEMSETUP AND EXPERIMENTAL RESULTS}

\section{A. System setup}

The real inverted pendulum used in the experiment is Googol inverted pendulum GLIP2003 as shown in figure 6 . It consists of the following components: a linear servo motion cart with a freely pivoted pendulum above it, optical encoder, motor, control hardware (control card GT-400-SVPCI), and control software.

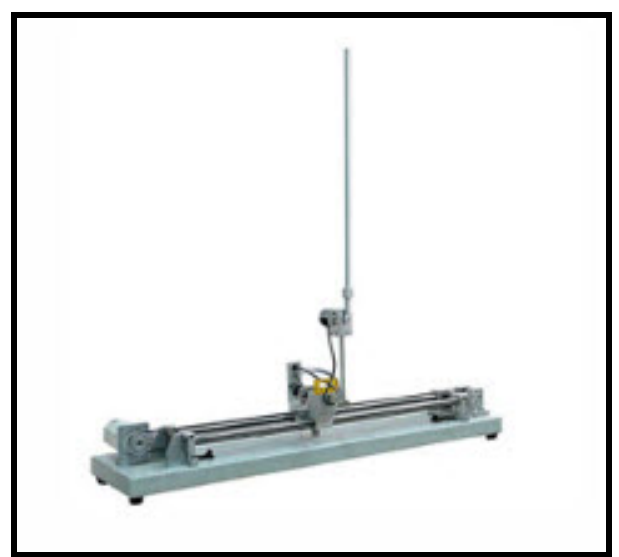

Figure 6 Googol Tech inverted pendulum.

Simulink is used as an interactive tool for modeling, simulation, and analyzing the system. Figure 7 shows the simulink model of the system used in experiment

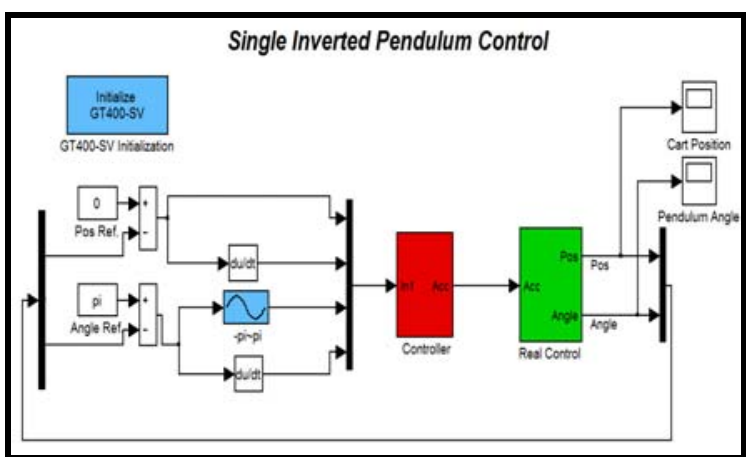

Figure 7 Simulink model of the inverted pendulum system.

Initially the pendulum is in vertically downward position. The pendulum rod is rotated by hand in the clockwise direction until feeling the control force.

\section{B. Experimental results}

The control algorithm in section 3 was applied to a real time inverted pendulum. Figure 8 and 9 shows the cart position and pendulum angle response respectively. It can be seen that the pendulum is stabilized in less than $2 \mathrm{~s}$, the cart oscillations during stabilization are very small about 0.5 $\mathrm{cm}$.

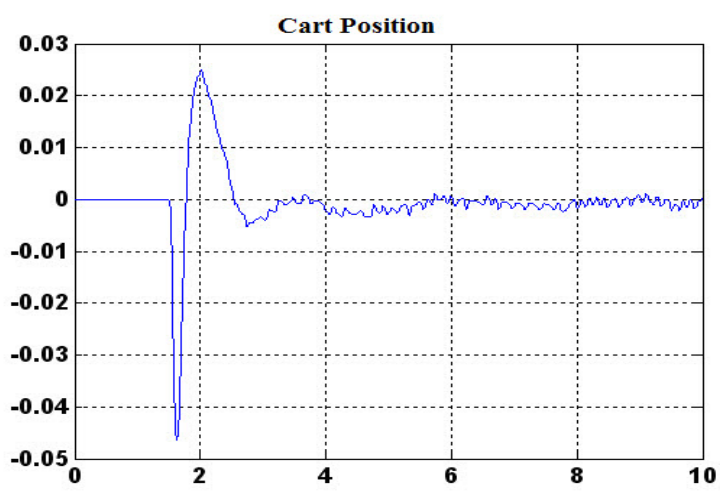

Figure 8 Cart position response.

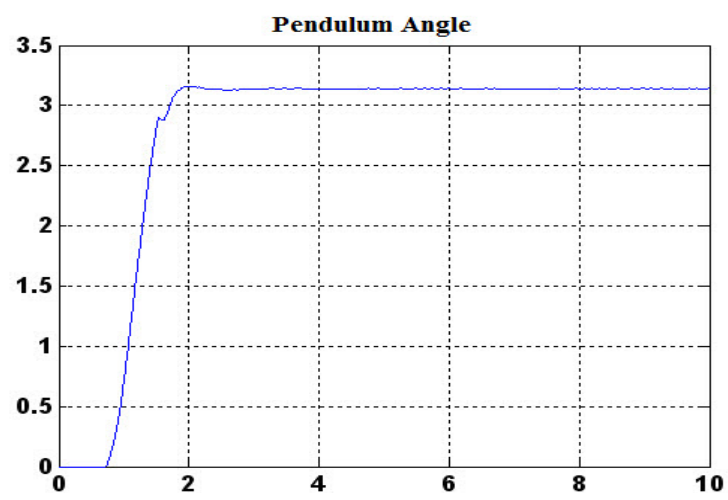

Figure 9 Pendulum angle responses.

Figure 10 shows the pendulum angle during stabilization when external disturbances are applied on the rod. The disturbances of magnitude $18^{\circ}$ and $-19^{\circ}$ are applied to the pendulum by hitting it at time $t=14 \mathrm{~s}$ and $\mathrm{t}=23.5 \mathrm{~s}$ 
respectively. The pendulum angle is stabilized in less than $2 \mathrm{~s}$ at each time of applying the external disturbance.

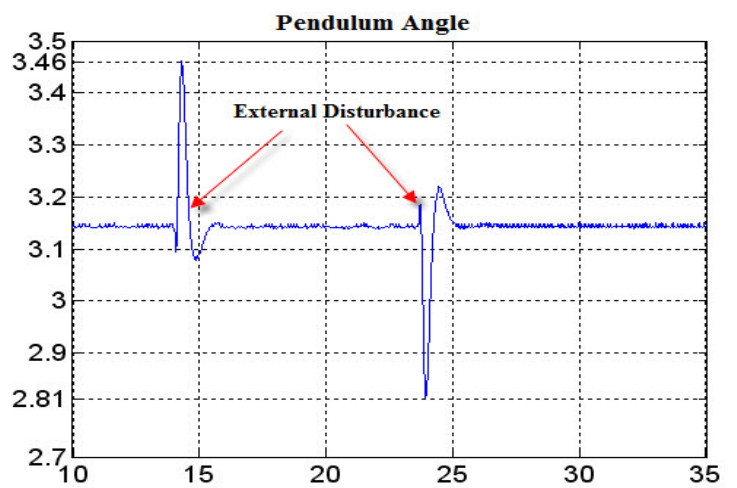

Figure10 Balancing of the Pendulum with external disturbances.

Figure 11 and 12 show the response of the system after changing the reference position from 0 to $0.1 \mathrm{~m}$ and vise reverse. It can be seen that the proposed controller is able to stabilize the pendulum system with less than $2 \mathrm{~s}$.

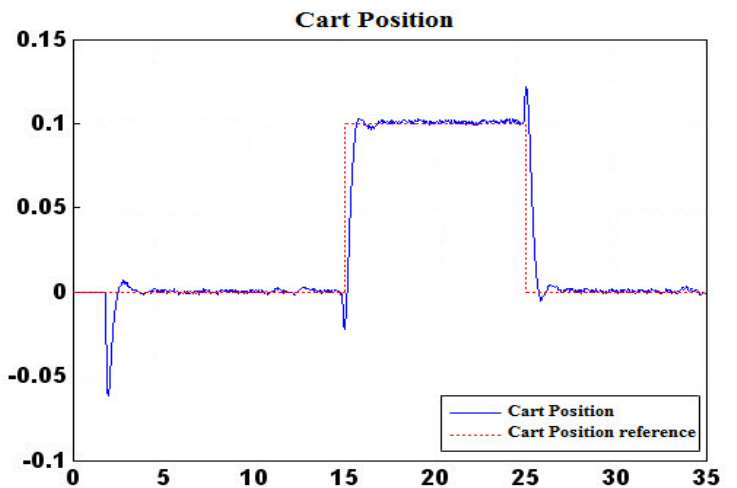

Figure 11 Cart position responses after changing the cart position.

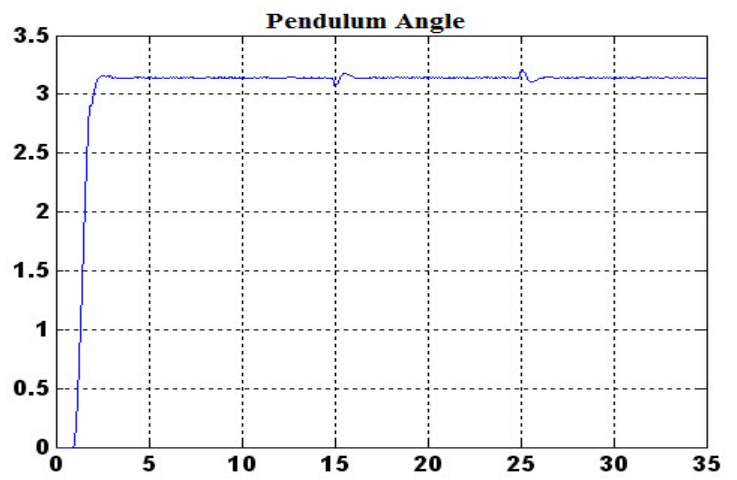

Figure 12 Pendulum responses after changing the cart position.

\section{CONCOLUSION}

A full state feed back controller using separation factor is proposed to stabilize a real single inverted pendulum. The system desired performance achieved by choosing a pair of poles as the dominant poles and separate the other poles using separation factor. The experimental results show that the proposed controller specified excellent performance,
$1.5 \mathrm{~s}$ settling time and low overshoot. In addition, the system has a good robustness, it can over come any external disturbances on cart or on pendulum rod and stabilize with in $2 \mathrm{~s}$.

\section{REFRENCES}

[1] F. Faizan, F. Farid, M. Rehan, and et al., "Implementation of discrete PID on inverted pendulum" Second international conference on education technology and computer (ICETC), vol.1(1), pp. 4851,2010 .

[2] T.C. Kuo, Y.J. Huang, and B.W. Hong, "Adaptive PID with sliding model control for the rotary inverted pendulum system" IEEE Int. conference on Advanced Intelligent Mechatronics, pp. 1804-1809, 2009.

[3] Baili Zhang and Jiang Guo Wang, "The analysis and simulation of first order inverted pendulum control system based on LQR" Third int. symposium on information processing (ISIP), pp. 447-449, 2010.

[4] L.B. Prasad, B. Tyagi, and H.O.Gupta, "Optimal control of nonlinear inverted pendulum dynamical system with disturbance input using PID controller \& LQR" IEEE Int. conference on control system computing and engineering, pp. 540-545, 2011.

[5] Hu Lingyan, Liu Guoping, Liu Xiaoping, and et al., "The computer simulation and real time stabilization control for the inverted pendulum system based on LQR" Fifth Int. conference on natural computation ICNC, vol. 6, pp. 438-442, 2009.

[6] Yanmei Liu, Zhen Chen, Dingyu Xue, and et al., "Real-time controlling of inverted pendulum by fuzzy logic" IEEE int. conference on automation and logistics (ICAL), pp. 1180-1183, 2009

[7] Chih Hui Chiu and Chun Chieh Chang "Wheeled inverted pendulum control based on model-free fuzzy control strategy" Proceeding of SICE annual conference, pp. 1604-1609, 2010.

[8] Cheng-Hao Huang, Wen-June Wang, and Chih-Hui Chiu, "Design and implementation of fuzzy control on a two-wheel inverted pendulum" IEEE transaction on industrial electronics, vol. 58 (7), pp. 2988-3001,2011.

[9] Jia-Jun Wang, "Simulation studies of inverted pendulum based on PID controllers" Simulation modeling practice and theory, vol. 19, pp. 440-449, 2011.

[10] Yan Lan and Minrui Fei, "Design of state-feedback controller by pole placement for a coupled set of inverted pendulums" $10^{\text {th }}$ int. conference on electronic measurement \&instruments (ICEMI), vol. 3, pp. 69-73, 2011.

[11] Huan Chun-E, Li Dong-Hai, and $\mathrm{Su}$ Yong, "Simulation and robustness studies on an inverted pendulum" Proceedings of the $30^{\text {th }}$ Chinese control conference, pp. 615-619, 2011.

[12] L.B. Prasad, H.O. Gupta, and B. Tyagi, "Intelligent control of nonlinear inverted pendulum dynamical system with disturbance input using fuzzy logic systems" Int. conference on recent advancements in electrical, electronics and control engineering, , pp. 136-141, 2011.

[13] Katsunhiko Ogata, "Modern Control Engineering" Fourth ed., Prentice Hall, New Jersey, 2002. 